\title{
A Method for Evaluation of the Quality of DNA Microarray Spots
}

\author{
Zhang Bao ${ }^{\dagger}$, Ma Wen-Li ${ }^{\dagger} *$, Hu Zi-You ${ }^{\dagger}$, Shi Rong ${ }^{\dagger}$, Song Yan-Bin ${ }^{\dagger}$ and Zheng Wen-Ling ${ }^{\ddagger} *$ \\ 'Department of Biochemistry, First Military Medical University, Guangzhou 510515 \\ Liuhuaqiao Hospital, Liuhua Road, Guangzhou 510000, P.R. China
}

Received 1 May 2002, Accepted 15 July 2002

\begin{abstract}
To establish a method to evaluate the quality of the printed microarray and DNA fragments' immobilization. The target gene fragments that were made with the restriction display PCR (RD-PCR) technique were printed on a superamine modified glass slide, then immobilized with UV cross-linking and heat. This chip was hybridized with universal primers that were labeled with cy3-dUTP, as well as cDNA that was labeled with cy3-dCTP, as the conventional protocol. Most of the target gene fragments on the chip showed positive signals, but the negative control showed no signal, and vice versa. We established a method that enables an effective evaluation of the quality of the microarrays.
\end{abstract}

Keywords: Detect, Gene chip, Microarray, RD-PCR, Quality

\section{Introduction}

Presently, the gene chip has been broadly used in the study of functional genomics, such as discovering the related genes of tumors (Cooper 2001; Nishizuka et al., 2002; Selaru et al., 2002) and induced differentiation (Dietz et al., 2000; Truckenmiller et al., 2001). In order to acquire an accurate result, the qualities in various respects of the chip must be carefully checked. Still, only a few methods for detecting the post-printed chip have been reported. In this study, we used the RD-PCR technique to make a cDNA microarray (Zheng et al., 1998), therefore the known sequence tags in both ends of target gene fragments are printed on the glass. A method was established to check the post-printed chip.

\section{Materials and Methods}

Materials The SH-SY5Y cell line that was used in this study was

*To whom correspondence should be addressed.

Tel: 86-20-61648210, 36622203; Fax: 86-20-61647755, 36622203

E-mail: wenli@fimmu.edu.cn a kind gift from Dr. Jingbo Zhang (Chinese Academy of Medical Sciences). The reagents that were used in this experiment are as follows: cell culture medium1640 and fetal bovine serum (GibcoBRL), guanidine thiocyanate (Sigma), DEPC (Sigma) reverse transcriptase AMV (Takara), Taq DNA polymerase (Takara), DNase I (Takara), cy3-dCTP and universal primer cy3UTTGGCTGGTGTGGATC (Amersham Pharmacia), CMT-GAPS coated glass (Corning Co.), and primers (primer A, 5'-gtaaaacgacgg ccagt-3'; primer B, 5'-caggaaacagctatgac-3') in a pMD18-T vector that were synthesized by Bo-Ya Corp., Shanghai.

Methods The total RNA of the SH-SY5Y cells was extracted by acid guanidinium thiocyanate-phenol-chloroform extraction (Chomczynski and Sacchi, 1987).

The target gene fragments preparation. The clones, selected from the library that was constructed by RD-PCR technique methods with a pMD18-T vector, were amplified with primers A and B. The PCR products were purified with CTAB (Zhang and Weiner, 2000), and the precipitation was dissolved in $10 \mu \mathrm{l}$ water. The concentration was determined with a Beckman DU530 UV spectrometer. The final concentration of each was adjusted to $0.3 \mathrm{mg} / \mathrm{ml}$ with DMSO and water. The DMSO concentration was $50 \%(\mathrm{v} / \mathrm{v})$.

The cDNA microarray was produced by spotting the target gene segments on special glass slides with Cartesian 5500 MicroArrayer, a target gene fragment was printed 3 times, then the DNA of the target genes were cross-linked by ultraviolet irradiation, baked in $80^{\circ} \mathrm{C}$ for $2 \mathrm{~h}$, and maintained in closed containers until application. Each array had 180 different gene fragments for a total of 540 spots.

Twenty $\mu \mathrm{g}$ total RNA was added to the labeling reaction. Five $\mu \mathrm{l}$ dATP, dGTP and dTTP $(10 \mathrm{mmol} / \mathrm{l})$ and $1 \mu \mathrm{ldCTP}(10 \mathrm{mmol} / \mathrm{l})$ $1.5 \mu \mathrm{l} \mathrm{cy} 3-\mathrm{dCTP}(1 \mathrm{mmol} / \mathrm{l}), 2 \mu \mathrm{g}$ oligo $\left(\mathrm{dT}_{18}\right), 15 \mathrm{U}$ AMVR, Nasin $20 \mathrm{U}$ and water were added to the total volume of $50 \mu \mathrm{l}$. The sample was incubated in $42^{\circ} \mathrm{C}$ for $1 \mathrm{~h}$. After purification with a DNA purification Kit (Takara), the purified and labeled DNA was successively dissolved in a pre-hybridization solution $(5 \times \mathrm{SSC}$, $0.1 \%$ SDS and $25 \%$ Formamide). The universal primer was resuspended in a hybridization solution $(25 \%$ formamide, $5 \times \mathrm{SSC}$, $0.1 \% \mathrm{SDS}$ ) to $10 \mu \mathrm{mol} / 1$. These products were respectively denatured in $95^{\circ} \mathrm{C}$ for 5 mins, centrifuged, then cooled. A $3.5 \mu \mathrm{l}$ 


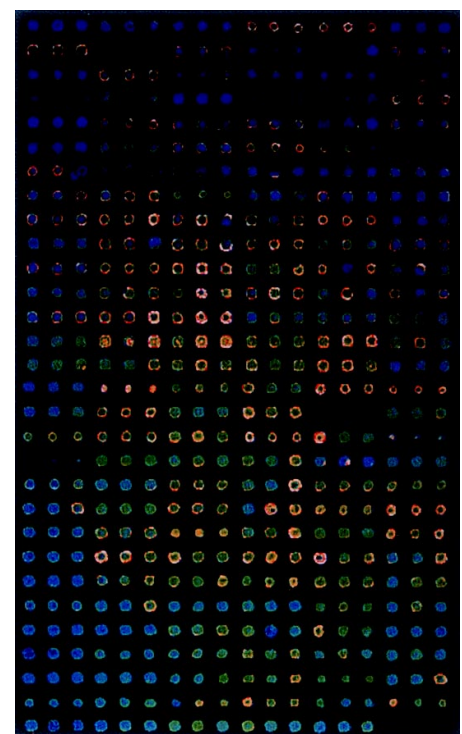

Fig. 1. The result of cy3-dUTP labeled universal primer's hybridization

hybridization mixture was added to the surface of the microarray, which had been previously immersed in a pre-hybridization medium for $45 \mathrm{~min}$. After a 8-h hybridization, the microarray was washed in $2 \times \mathrm{SSC} / 0.1 \% \mathrm{SDS}, 0.1 \times \mathrm{SSC} / 0.1 \% \mathrm{SDS}, 0.1 \times \mathrm{SSC}$, $\mathrm{H}_{2} \mathrm{O}$ and alcohol, then the chip was desiccated at room temperature. The chips were scanned with Scanarray lite (GSI Lumonics Co).

\section{Results}

Figure 1 shows the hybridization result of the Cy3-dUTP labeled universal primer under a condition of $80 \%$ laser energy and $70 \%$ GMT. There was no signal on the negative control spot (printing 50\% DMSO) on the last row. In the lines of 6,17 , there were three points that showed no signal. In the lines of 18,19 , there were individually three points where the signal was very faint when probed with a cy3 labeled sequence tag. When hybridized with the cy3-dCTP labeled cDNA, it showed that there was no signal at the same place as with the universal primer (Fig. 2). There are also six points in the two lines (lines of 15,20 ) where the signals did not appear.

\section{Discussion}

Following the completion of the Human Genome Project, the post-genomics era will focus on the gene expression patterns of all kinds of organisms and gene functional research. The gene chip technique has become a powerful tool for completing this task, because the chip technology has been characterized as the platform of high output, sensitivity, speed, and accuracy.

Currently, cDNA microarray is most-commonly used to study gene expression profiling. Though many of the processes have been automated, the operation is still

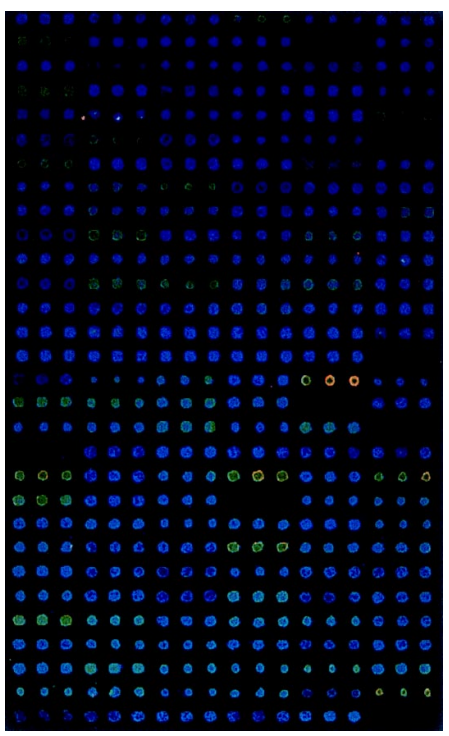

Fig. 2. The result of cy3-dCTP labeled cDNA's hybridization

complicated. The procedure consists of the following: disposing of the substrate, preparation of target genes, printing, immobilizing, labeling of the probe, hybridizing, scanning, and analyzing. The high quality of the microarray is a prerequisite for achieving reliable results. So, there are many quality control technologies in the process, such as the treatment of the slide surface, reduction of the noise, selection of target gene fragments. In the process of post-printing, there are few effective methods to check the quality. Some target gene fragments were misprinted. This resulted in there being a misdetection in the analyzing procedure. Some of the investigators used certain fluorescent substances, as well as video surveillance; however, this cannot detect the immobilization quality. Because the DNA quantity on the chip is tiny; therefore, satisfactory results are generally difficult to achieve (personal correspondence).

The target genes that are fixed in the gene expressionprofiling chip have two forms. One is part of the genes; the other is the full length of the genes. Partial genes are produced by amplification with specific primers (Richmond et al., 1999; Wei et al., 2001). Some companies and research units have developed software that quickly seeks the primers; for example PrimeArray (Raddatz et al., 2001), arraydesigner 2.0 (Premier Biosoft International Co.). The full length of the gene products that are amplified from the clone vector (Maxwell and Davis, 2000) have the sequence tag, but the tag contains a low complexity sequence, such as polyG or polyT. Consequently, they do not have a common sequence tag that is suitable for hybridization detecting. In this experiment, we used the RD-PCR technique to prepare the target gene fragments; the length of the fragments ranges from $250 \mathrm{bp}$ to $750 \mathrm{bp}$. This makes hybridization dynamics uniform. Another feature is that the fragments possess a general sequence tag. Its $\mathrm{Tm}$ is about $60^{\circ} \mathrm{C}$, which is correct for stringent 


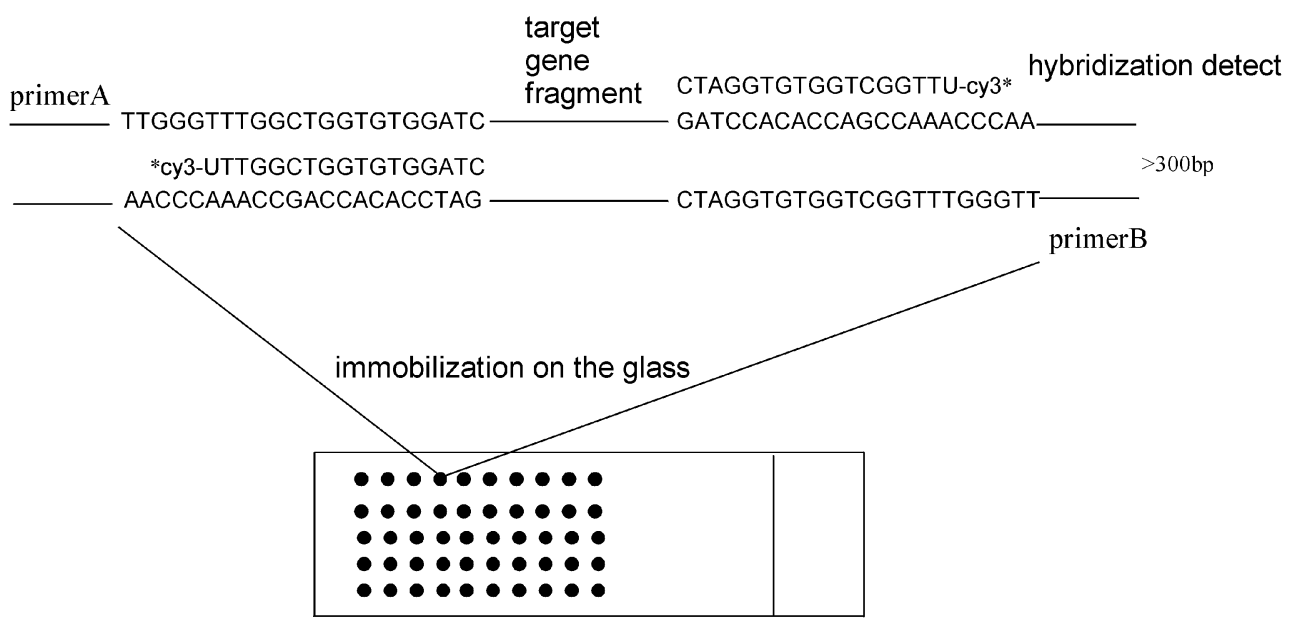

Fig 3. The principle of detection with cy3-dUTP labeled universal primer.

hybridization. We used the cy3-dUTP labeled universal primer to hybridize with the chip. The result showed that there were two gene fragments that showed no signals, and two genes that were very faint. When the cy3-dCTP labeled cDNA was hybridized, two target genes (in the lines of 6,17 ) showed the same results as those of the labeled universal primers, while the other two genes (in the lines of 18, 19, whose signals were very feeble in the universal primer) had no signals. This may be because the fixed volume on the slide was tiny. The additional two target genes (in the lines of 15, 20) showed no signals, which may be because of the low gene expression level and the sensitivity of the clone that was selected with RD-PCR. This indicates that the four gene fragments might be misprinted or immobilized poorly. At the same time, it was possible to conclude the quality of printing from the size and extent of the circle of points. Figure 3 shows the principle of universal primer hybridization.

The following may have caused the misprinting in the printing procedure: (1) The sample volume in the 384 wells plate was too large. We used the pins that were purchased from Telechem Co. If the sample volume is more than 15$20 \mu \mathrm{l}$, it will result in an obvious reduction of printing materials in the later spotting stages. Usually, the sample volume of one transferring can print $150-200$ points. (2) In the target gene solution, there was some insoluble substance, which could block the pins. There are generally four methods to precipitate the PCR products; with ethanol, isopropanol, CTAB or the filter membrane (Telechem Co.). DNA is often difficult to dissolve in water with ethanol or isopropanol precipitation. DNA sedimentation is easily resuspended with $\mathrm{CTAB}$, but the protocol time is too long. There is less insoluble material with the membrane filtration method, but it is expensive. (3) Particular care must be given to the pins. The pins need to be correctly stored and cleaned with a special solution, or else their usability will be compromised.

In this paper, we examined the chips on which the gene fragments had been printed 120 times. A misprinting phenomenon or a less fixed-volume on the slide existed, which indicates that it is important to examine the spot quality in order to ensure that the microarray results are reliable. Detection with cy3-dUTP labeled universal primers is a simple and effective method to evaluate the microarrays that are made with the RD-PCR technique.

\section{References}

Chomczynski, P. and Sacchi, N. (1987) Single-step method of RNA isolation by acid guanidinium thiocyanate-phenolchloroform extraction. Anal. Biochem. 162, 156-159.

Cooper, C. S. (2001) Applications of microarray technology in breast cancer research. Breast Cancer Res. 3, 158-175.

Dietz, A. B., Bulur, P. A., Knutson, G. J., Matasic, R. and VukPavlovic, S. (2000) Maturation of human monocyte-derived dendritic cells studied by microarray hybridization. Biochem. Biophys. Res. Commun. 275, 731-738.

Maxwell, S. A. and Davis, G. E. (2000) Differential gene expression in p53-mediated apoptosis-resistant vs. apoptosissensitive tumor cell lines. Proc. Natl. Acad. Sci. USA 97, 13009-13014.

Nishizuka, I., Ishikawa, T., Hamaguchi, Y., Kamiyama, M., Ichikawa, Y., Kadota, K., Miki, R., Tomaru, Y., Mizuno, Y., Tominaga, N., Yano, R., Goto, H., Nitanda, H., Togo, S., Yasushi, Y., Hayashizaki, Y. and Shimada, H. (2002) Analysis of gene expression involved in brain metastasis from breast cancer using cDNA microarray. Breast Cancer. 9, 26-32.

Raddatz, G., Dehio, M., Meyer, T. F. and Dehio, C. (2001) PrimeArray: genome-scale primer design for DNA-microarray construction. Bioinformatics. 17, 98-99.

Richmond, C. S., Glasner, J. D., Mau, R., Jin, H. and Blattner, F. R. (1999) Genome-wide expression profiling in Escherichia coli K-12. Nucleic Acids Res. 27, 3821-3835.

Selaru, F. M., Zou, T., Xu, Y., Shustova, V., Yin, J., Mori, Y., Sato, F., Wang, S., Olaru, A., Shibata, D., Greenwald, B. D., Krasna, M. J., Abraham, J. M. and Meltzer, S. J. (2002) Global gene expression profiling in Barrett's esophagus and esophageal cancer: a comparative analysis using cDNA microarrays. 
Oncogene 17, 475-478.

Truckenmiller, M. E., Vawter, M. P., Cheadle, C., Coggiano, M., Donovan, D. M., Freeds, W. J. and Becker, K. G. (2001) Gene expression profile in early stage of retinoic acid-induced differentiation of human SH-SY5Y neuroblastoma cells. Restor. Neurol. Neurosci. 18, 67-80.

Wei, Y., Lee, J. M., Richmond, C., Blattner, F. R., Rafalski, J. A. and LaRossa, R. A. (2001) High-density microarray-mediated gene expression profiling of Escherichia coli. J. Bacteriol. 183, 545-556.

Zhang G. J. and Weiner J. H. (2000) CTAB-mediated purification of PCR products. Biotechniques 29, 982-986.

Zheng, W., Ma, W. and Waes, C. V. (1998) The differential display of polyA polymerase in tumor cells of differential malignancy; in Investigation on Cell Modulation, Ye XS et al. (eds.), pp. 73-79, Uniform Medical Publishing, Beijing. 